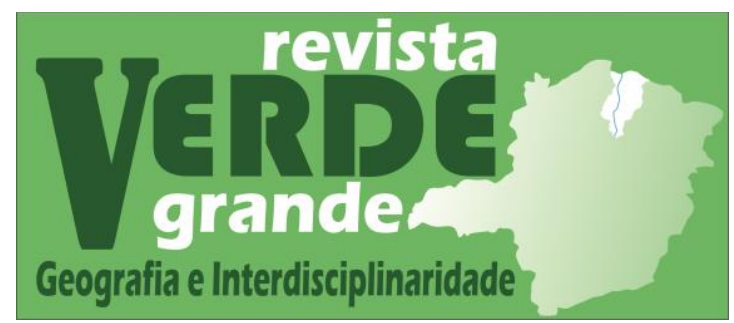

Volume 01, n‥ 01, 2019

https://www.periodicos.unimontes.br/index.php/verdegrande

\title{
MAPEAMENTO DO NÍVEL FREÁTICO: UMA ANÁLISE SUBSIDIADA POR GEOTECNOLOGIA
}

\author{
Mapping of the freatic level: a subsidized analysis by geotechnology
}

\author{
Manoel Reinaldo Leite ${ }^{1}$ https://orcid.org/0000-0003-3744-5903 \\ Lucas Augusto Pereira da Silva ${ }^{2}$ https://orcid.org/0000-0001-5504-9029 \\ Caio Vinícios Leite Sampaio $^{3}$ https://orcid.org/0000-0001-5402-5500
}

\footnotetext{
${ }^{1}$ Professor do Departamento de Geociências - Universidade Estadual de Montes Claros. E-mail: leitemanoelreinaldo@gmail.com

${ }^{2}$ Mestrando em Geografia - Universidade Estadual de Montes Claros. E-mail: lucaskaio1605@gmail.com

${ }^{3}$ Graduado e Geografia - Universidade Estadual de Montes Claros. E-mail: caio@agbrasilweb.com.br
}

\begin{abstract}
Resumo
Este trabalho teve como objetivo mapear o nível freático da Bacia Hidrográfica do Rio São Lamberto, situada na mesorregião Norte de Minas Gerias. Este mapeamento propôs utilizar de dados de campo (poços artesianos) para configurar tecnicamente o nível freático da área de estudo, espacializando por meio de interpolação com o IDW (Inverse Distance Weighting). Este estudo se mostrou forte indicador para mapeamentos de nível freático, isso sendo de extrema importância para estudos ambientais, norteamentos de perfuração de poços, análises dinâmicas entre variáveis morfométricas e recursos hídricos. Do ponto de vista técnico, este trabalho se apresenta como uma proposta metodológica que pode vir a beneficiar diferentes escalas e áreas do conhecimento, e, podendo dar suporte técnico às políticas públicas para a gestão dos recursos hídricos. As Geotecnologias se apresentam com boas opções para estudos que necessitam de análises do espaço geográfico e, sobretudo considerando a dinâmica hídrica.
\end{abstract}

Palavras-chave: Nível Freático, Geotecnologias e Bacia do Rio São Lamberto.

\begin{abstract}
This work aimed to map the groundwater level of the São Lamberto River Basin, located in the northern Minas Gerias mesoregion. This mapping proposed to use field data (artesian wells) to technically configure the groundwater level of the study area, spatializing through interpolation with IDW (Inverse Distance Weighting). This study proved to be a strong indicator for groundwater level mapping, which is extremely important for environmental studies, well drilling guidelines, dynamic analyzes between morphometric variables and water resources. From the technical point of view, this work presents itself as a methodological proposal that may benefit different scales and areas of knowledge, and may provide technical support to public policies for water resources management. Geotechnologies are presented with good options for studies that require analysis of the geographical space and, especially considering the water dynamics.
\end{abstract}

Keywords: Water Level, Geotechnologies and São Lamberto River Basin. 


\section{Mapeamento do nível freático: uma análise subsidiada por geotecnologia}

Manoel Reinaldo Leite; Lucas Augusto Pereira da Silva; Caio Vinícios Leite Sampaio

\section{Introdução}

A evolução das civilizações desde os primórdios da história humana se deu às margens de recursos hídricos com intuito de manter sua organização; com suprimento de necessidades fisiológicas e as primeiras ascendências da agricultura, e mesmo que rústica, os recursos naturais perduraram para tais civilizações.

No entanto, com o passar dos séculos, o crescimento populacional vêm fomentando a demanda por recursos naturais de maneira exponencial, e isso acarretou em mudanças na oferta natural, sobreutudo no que tange a água. Einstein já dizia que o espaço é continuum, estando em pleno devir, ou seja, vivenciando mudanças ao longo do tempo (HAWKING, 1988).

Destarte, essas mudanças fomentam de maneira significativa a busca por técnicas que possam conduzir o Homem a novas formas de obter este bem (água), e, a compreensão analítica para tal questão é essencial. Naturalmente a água em suas diversas formas de entrada (input) no sistema terra se espacializa de maneira sazonal, reflexo de dinâmicas meteorológicas, como visto em Tubelis e Nascimento (1980). No entanto, esta dinâmica vem tendo prolongações tanto para maiores períodos chuvosos, quanto para estiagens.

$\mathrm{E}$, essa questão fomenta a busca de água nos reservatórios naturais da Terra, bem como as águas subterrâneas. Vale salientar que, essa busca por águas subterrâneas é feita desde os tempos antigos, em que nas regiões menos chuvosas o homem buscava-a (LEINZ e AMARAL, 2001). Dentre as formas de chegar ao uso desta água, Lienz e Amaral (2001) que se encontra na Zona Saturada, abaixo da Zona de Aeração e da Zona Piezométrica e/ou Hidroestática, são os poços artesianos. E, essa forma de obtenção vem solucionando vários problemas socioeconômicos em regiões semiúmidas como no caso da área de estudo.

No entanto, o conhecimento sobre o nível freático é escasso, ou seja, o entendimento de onde se situa a água nas cotas altimétricas do relevo, o que é imprescindível para tais atividades, já que a identificação pontual se torna árdua pela grande quantidade de variáveis que necessitam de compreensão, tais como a geologia, geomorfologia, pedologia, litologia e ademais.

Com isso, mapear o nível freático é algo elementar para a captação de água subterrânea, e, este mapeamento deve dispor de Geotecnologias, haja vista que as mesmas possuem a capacidade de síntese do espaço geográfico de maneira ímpar.

Face exposto, este trabalho teve como objetivo mapear o nível freático da Bacia Hidrográfica do Rio São Lamberto, situada na mesorregião Norte de Minas Gerias. Este 


\section{Mapeamento do nível freático: uma análise subsidiada por geotecnologia}

Manoel Reinaldo Leite; Lucas Augusto Pereira da Silva; Caio Vinícios Leite Sampaio

mapeamento propôs utilizar de dados de campo (poços artesianos) e procedimentos laboratoriais, bem como o interpolador IDW (Inverse Distance Weighting) para configurar tecnicamente o nível freático da área em tese. Foi regido um relatório técnico com a metodologia desenvolvida e resultados alcançados após a objetivação deste estudo em forma de artigo científico.

Este trabalho tem como justificativa a falta de estudos com uso de Geotecnologias que possui como proposta analítica a compreensão do nível freático, e, também pelo fato deste bem tão essencial (água) ser pautado como discussão central nos últimos anos no Norte de Minas Gerias.

\section{CARACTERIZAÇÃo DA ÁREA DE ESTUDO}

A área de estudo está situada na mesorregião Norte de Minas Gerais, possui 11,82 $\mathrm{Km}^{2}$, e está entre as latitudes de 8140000 e $8090000 \mathrm{~N}$ e longitudes 560000 e $630000 \mathrm{E}$, sendo pertencente às unidades municipais de: Montes Clatos, São João da Lagoa, Jequitaí e Claro dos Poções, conforme a Mapa 1:

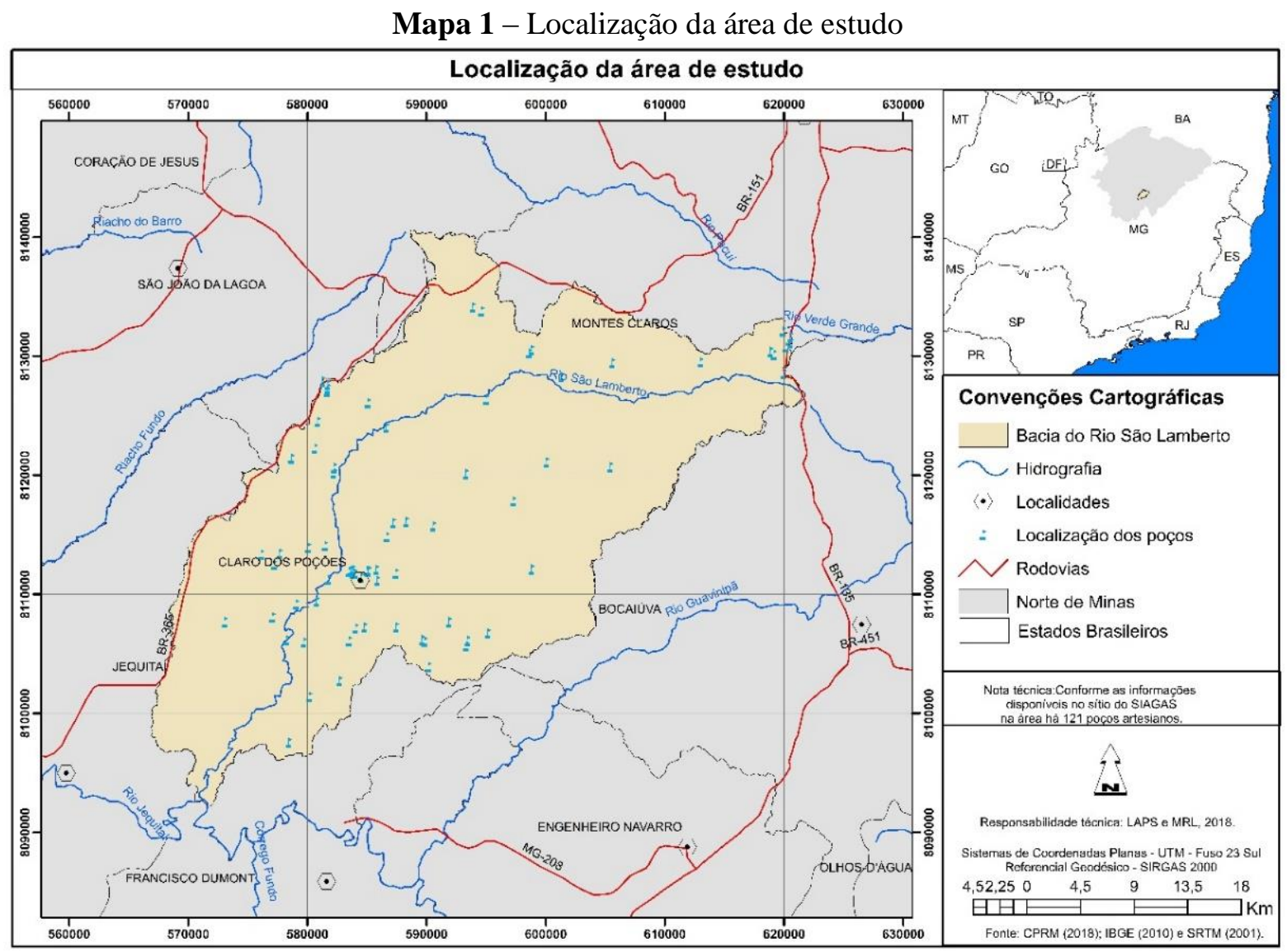

Fonte: Os autores 


\section{Mapeamento do nível freático: uma análise subsidiada por geotecnologia}

Manoel Reinaldo Leite; Lucas Augusto Pereira da Silva; Caio Vinícios Leite Sampaio

Do ponto de vista logístico, esta área é privilegiada pelo entroncamento rodoviário em que se encontra (vide Mapa 1), destacando as rodovias: BR 365 na porção oeste, BR 151 a norte/noroeste, a leste e nordeste a BR 135; salienta-se o fato desta área possuir ao seu norte, porção do município de Montes Claros, sendo este o maior polo econômico do Norte de Minas Gerais.

No tocante ao quadro geofísico esta bacia possui como rio principal o São Lamberto, tendo sua nascente pertencendo ao território do município de Montes Claros, e desagua no Rio Jequitaí ao Sul da bacia. Conforme os dados do IBGE (2010), a sudeste da área está o Rio Guavinipã, que traceja os municípios de Bocaiúva e Engenheiro Navarro cujo os mesmos fazem limite com a bacia, ao Norte e Nordeste estão situados os Rios Pacuí e Verde Grande, a oeste está o Riacho fundo e a Sul os Rio Jequitaí e Córrego fundo.

Conforme dados da CODEMIG (2015) (após tratamento computacional), no que tange à hierarquia fluvial da área de estudo, apresentam-se desde rios de primeira ordem a quinta ordem, isso de acordo com a classificação de Strahler (1957).

Em termos geológicos, de acordo com dados da CODEMIG (2015), a bacia do Rio São Lamberto possui uma vasta variabilidade quanto às suas unidades geológicas, tendo: Subgrupo Espinhaço Superior, Formação Jequitaí, Grupo Urucúia, Cobertura Superficial Indiferenciada, Grupo Bambuí e Subgrupo Paraopeba (estas unidades serão debatidas na discussão). Quanto aos aspectos geomorfológicos, esta área possui: relevos das Chapadas do Rio São Francisco e Depressão Alto-Médio São Francisco (ALMEIDA et al, 2017). As cotas altimétricas que são dados essenciais para este artigo, variam de 564 metros a 1088, com amplitude de 524 metros (SRTM, 2001).

No que diz respeito ao contexto litológico, as rochas que compõem esta bacia são: metamórficas, sedimentares, sedimentar glacial e sedimentos inconsolidados. De acordo com Almeida et al (2017), na área de interesse analítico, no que diz respeito aos aspectos pedológicos, possui três tipos de solos, sendo argilossolo vermelho-amarelo distrófico, neossolo litólico, eutrófico e latossolo vermelho distrófico, tendo 31,7\%, 0,7\% e 59\% respectivamente.

No que se refere ao quadro vegetacional, a área em tese é composta por áreas de Cerrado (tendo sentido restrito, formações campestres, cerradão em topos de chapada e etc), e resquícios de Mata Atlântica, sendo Floresta Estacional Semidecidual e decidual.

De acordo com a classificação climática de Köppen, o clima predominante é o tropical, representado pela sigla $A w$, possuindo assim inverno seco e verão chuvoso. 


\section{Mapeamento do nível freático: uma análise subsidiada por geotecnologia}

Manoel Reinaldo Leite; Lucas Augusto Pereira da Silva; Caio Vinícios Leite Sampaio

Diante do contexto de antropização, no território da área de estudo, encontra-se extensões de sistemas agropastoris em diferentes estágios de conservação e áreas de cultivos.

Segundo os dados da CPRM (2018) dentro dos limites da bacia, estão registrados 121 poços artesianos, sendo espaçados e distribuídos em todos os paralelos do território (vide Mapa 1).

\section{PROCEDIMENTOS TÉCNICOS OPERACIONAIS}

Para execução este trabalho subdividiu-o em 4 etapas para que houvesse uma melhor coerência técnica e científica para a análise, sendo estas etapas: análise bibliográfica; seleção em sítios oficiais dos vetores para mapeamento geofísico e político da área e ainda nesta etapa foi feita a seleção de produto de Sensoriamento Remoto coleta de dados sobre nível estático e os pontos georreferenciados dos poços artesianos; e a análise por Geotecnologias. Os processos metodológicos realizados neste trabalho estão representados também no fluxograma 01:

Fluxograma 01 - etapas metodológicas

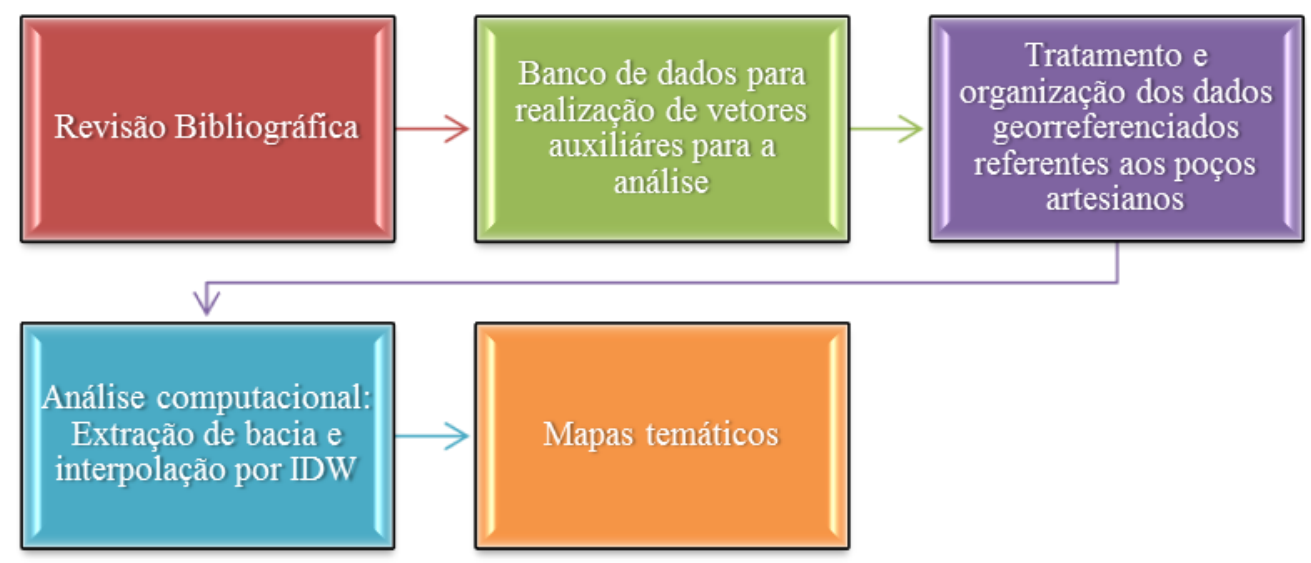

Fonte: Processo metodológico. Responsabilidade técnica: MRL, 2018.

$1^{\circ}$ etapa: buscou na literatura estudos em que possuíam conhecimentos semelhantes a este, bem como a busca da compreensão de fenômenos hidrológicos em conjunto da Geologia Geral e Geomorfologia, das aplicações técnicas das Geotecnologias às análises tangentes aos recursos hídricos, esses estudos estão apresentados no decorrer do corpo do texto. 


\section{Mapeamento do nível freático: uma análise subsidiada por geotecnologia}

Manoel Reinaldo Leite; Lucas Augusto Pereira da Silva; Caio Vinícios Leite Sampaio

$2^{\circ}$ etapa: esta parte do processo consistiu na obtenção de vetores de Geologia, Litologia, hidrografia e limites municipais, fornecidos pela Companhia de Pesquisas de Recursos Minerais (CPRM) e Instituto Brasileiro de Geografia e Estatística (IBGE), respectivamente. Ainda nesta etapa foi selecionado o produto de Sensoriamento Remoto, no caso o Modelo de Elevação Digital (MDE), com sua elaboração pelo Missão Topográfica Radar Shuttle (SRTM), dispondo das folhas SE-23-X-A e SE-23-X-C.

$3^{\circ}$ etapa: no sítio do Sistema de Informações de Águas Subterrâneas (SIAGAS) foram coletados pontos georreferenciados em extensão de shapefile, para serem representados e espacializados em ambiente computacional, bem como a análise de planilhas dispostas nos arquivos, onde estas possuíam valores de: nível estático (NE), nível dinâmico (ND), vazão (sendo a água retirada dos poços) e entre outros dados, mas neste caso fez uso incisivo do NE.

$4^{\circ}$ etapa: este momento foi essencial para a análise, já que dispôs dos produtos supracitados nas etapas acima para dar sequência à análise. Inicialmente foram gerados mapas temáticos com dados de hipsometria, unidades geológicas, litologia, localização de área de estudo bem como a representação dos poços artesianos. E na sequência, com o MDE foi delimitada a bacia do Rio São Lamberto, através de um processo de interação computacional no software de Geoprocessamento, ArcGis 10.3.1 através da plataforma ArcMap, salienta-se que este software é licenciado pelo Laboratório de Geoprocessamento da Universidade Estadual de Montes Claros - UNIMONTES.

O processo de interação mencionado, foi feito através do seguinte procedimento: Extensão Espatial Analyst Tools > Ferramenta Hidrology > Flow Direction $>$ Sink $>$ Fill $>$ Flow Direction>Flow Accumulation> Map Algebra>Stream Feature> Basin. Por fim, chegando nesta última etapa são geradas as drenagens na bacia e o limite da mesma, Silva e Leite (2017) descrevem este método de extração.

Após isto, foi feita a extração do limite da bacia no MDE, onde consiste os dados em $\mathrm{x}, \mathrm{y}, \mathrm{z}$, sendo as localizações dos pontos nas duas variáveis iniciais e na terceira é dada a altitude das localidades. Esta extração foi feita pela ferramenta extract by mask, e após esta extração, deu início ao processo com os pontos dos poços, estando georreferenciados.

Extraiu-se os pontos dos poços (sendo 121 poços) no MDE através da ferramenta extract value to point, conseguinte a isso teve-se os valores da altitude do relevo onde se encontram os poços em uma parte da planilha do shapefile de pontos, essa planilha foi exportada para o Excel a fim de posterior geração de gráficos. 


\section{Mapeamento do nível freático: uma análise subsidiada por geotecnologia}

Manoel Reinaldo Leite; Lucas Augusto Pereira da Silva; Caio Vinícios Leite Sampaio

Tendo em posse os dados de cotas altimétricas dos poços, foi feito um processo interativo, entre o NE e as cotas altimétricas. O nível estático, conforme Leinz e Amaral (2001) pode ser compreendido também como nível hidroestático, em que a água se encontra inerte abaixo da camada piezométrica, e, os valores de NE é compreendido como a profundidade em que o técnico perfurou a superfície até atingir a água no subsolo. Destarte, realizou-se uma equação básica entre o NE e o ARP (Altitude do Relevo dos Poços) para geração do NF (Nível Freático), conforme na equação 1:

$$
N F=A R P-N E
$$

Com esta subtração básica, obteve-se a diferença entre a altitude do relevo dos poços e o nível estático, e, esta diferença é o nível freático, ou seja, como o NE é representado pela profundidade (dada em metros) da perfuração dos poços até atingir a água, ao analisar a altitude do relevo onde se situa os poços tendo esta subtração do NE, terá em seguida a posição/localização do nível da água no relevo. Estes dados foram salvos como shapefile para posterior uso.

Após ter esta diferença e consequentemente a localização pontual do NF, buscou-se compreender o NF espacializado para toda a extensão da bacia do rio São Lamberto. Para tanto, é necessário dispor de técnicas inerentes ao Geoprocessamento, sobretudo de métodos de interpolação, que " é uma técnica utilizada para a estimativa do valor de um atributo em locais não amostrados, a partir de pontos amostrados na mesma área ou região" (JACOB; YUNG, 2006. p.7) e para esta análise utilizou-se a Ponderação do Inverso das Distâncias (IDW) do inglês Inverse Distance Weighting, um interpolador acoplado na plataforma ArcMap.

O IDW considera as amostras informadas no campo de entrada, e, a partir dessas amostras estima valores para distâncias circunvizinhas onde não possuem dados amostrais. Este interpolador é bastamente utilizado no meio técnico e científico para diversas análises e em diferentes campos.

Essa interpolação se deu utilizando o shapefile com as informações de nível freático dos poços. Inicialmente é preciso preparar o ambiente computacional para esta atividade interativa, assim seguiu o processo: Geoprocessing > Envinronments > indicação da aplicação dos dados a serem interpolados, que neste caso foi o limite da Bacia, posterior a esta preparação, foi acionada a extensão interpolation e após a ferramenta $I D W$, sendo o 
interpolador, após este procedimento tem-se em ambiente computacional o raster interpolado. Por fim, foram gerados ainda no ArcGis os mapas temáticos.

\section{RESULTADOS E DISCUSSÃO}

A compreensão do nível freático necessita abordagens pluralistas, buscando fomentar discussões em diversos prismas, e, diante disso é preciso entender como o mesmo acontece e sobretudo considerando o ciclo hidrológico e a inserção de poços artesianos. Nas figuras 1 e 2 está representada o ciclo hidrológico e consequentemente a origem das águas subterrâneas:

Figura 1 - Ciclo Hidrológico e subterrânea.

Figura 2 - Detalhes do ciclo hidrológico.
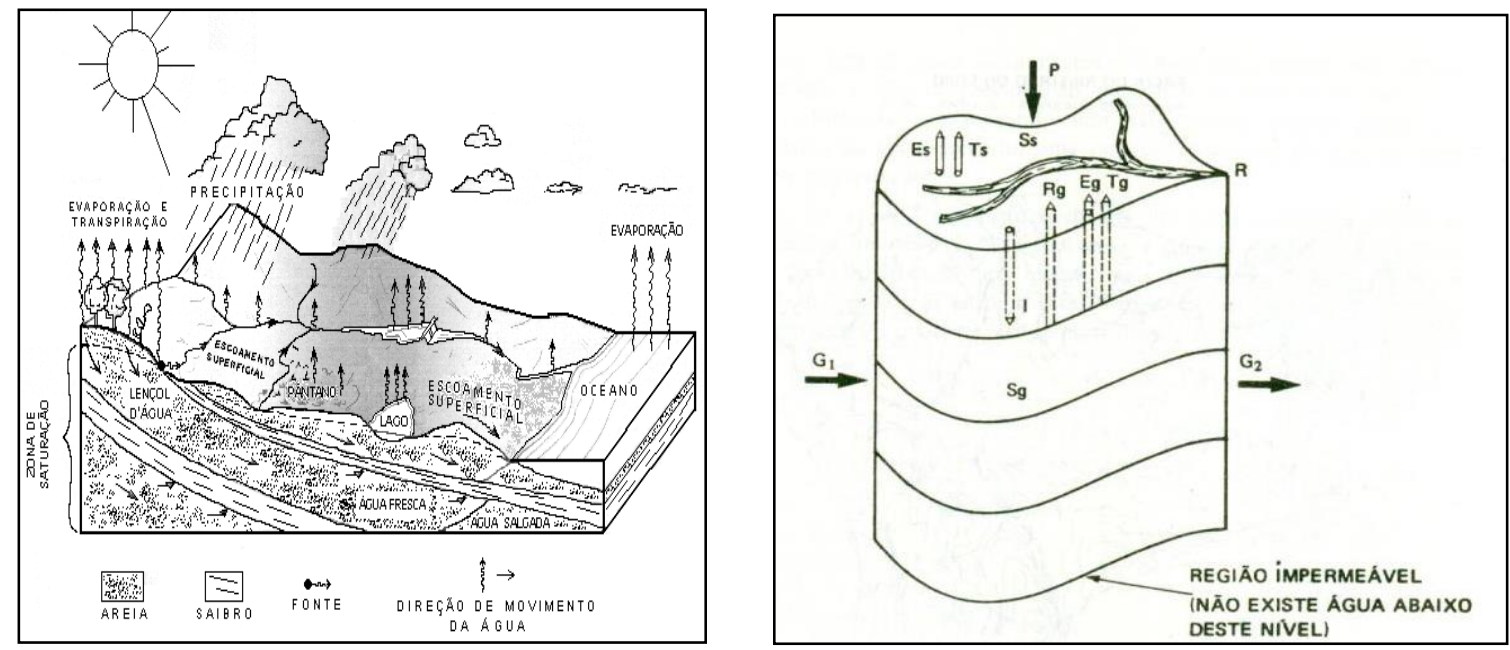

Fonte: Apostila elementos da hidrologia aplicada.

Fonte: VILELLA E MATTOS (1975).

Observa-se vários elementos nas figuras acima, tendo primordialmente a estrela Sol como geratriz da energia para as demais atividades exercidas na superfície terrestre, com a sua irradiação de energia, fornece aos elementos disponibilidade energética para seus processos biológicos, químicos e físicos.

Em seguida é importante analisar uma forma essencial de entrada de água em sistema hidrológico, tratando-se assim da precipitação, posteriormente já é possível observar a influência do relevo e suas cotas altimétricas elevadas para a captação e recepção das descargas hídricas pelas chuvas, onde as cabeceiras acabam (os topos) desenvolvem função ímpar no armazenamento de água e ditando os fluxos de escoamento superficial de uma dada bacia hidrográfica. 


\section{Mapeamento do nível freático: uma análise subsidiada por geotecnologia}

Manoel Reinaldo Leite; Lucas Augusto Pereira da Silva; Caio Vinícios Leite Sampaio

Logo em sequência, observa-se as formas de troca de massa entre a superfície e a atmosfera, esta superfície supracitada pode ser área vegetada, ou desnuda de vegetação e extensões de corpos hídricos. Estas trocas são denominadas de evaporação e transpiração. A evaporação é um processo físico exercido pela influência da incidência da radiação solar (TUBELIS e NASCIMENTO, 1980), tendo a transformação de moléculas de água em vapor de água, ocorrendo em lagos, rios, oceanos e demais superfícies úmidas (VELOSO et al 2013). Já a transpiração é um processo biológico que ocorre nas plantas (ALLEN et al 2002), que tende a variar com disponibilidade energética, de água, nutrientes, variações climáticas sazonais, ventos, umidade e variações fenológicas, bem como abertura ou fechamento de estômatos, sistema radicular e área foliar, e entre outros elementos.

Em seguida, observam-se os demais processos do ciclo hidrológico dentro de uma unidade hidrográfica, sendo o escoamento superficial, onde o movimento da água é impulsionado pela forma da bacia, bem como seu índice de compacidade, tendo destino a foz da bacia como visto em Vilella e Mattos (1975). A infiltração a água no solo é um momento escalar deste processo, sobretudo considerando a porosidade do solo e sua capacidade de percolação de água. Outro elemento do ciclo hidrológico é o escoamento subterrâneo, que ocorre abaixo do solo tendo também direção os corpos hídricos a jusante, conforme visto nos autores supracitados.

Do ponto de vista da compreensão da divisão/estrutura das camadas que adentram a superfície da terra, pode-se entendê-la da seguinte forma: Zona de aeração/ subsaturada que é a área onde a planta/vegetação dispõe de suprimento hídrico pelo sistema radicular, possui também a área piezométrica, ou nível hdroestático, e abaixo a zona saturada de água, e em sequência possui a camada impermeável (LEINZ e AMARAL, 2001). Na figura 3 está esta representação de forma mais detalhada: 
Figura 3 - Representação esquemática da distribuição da água subterrânea

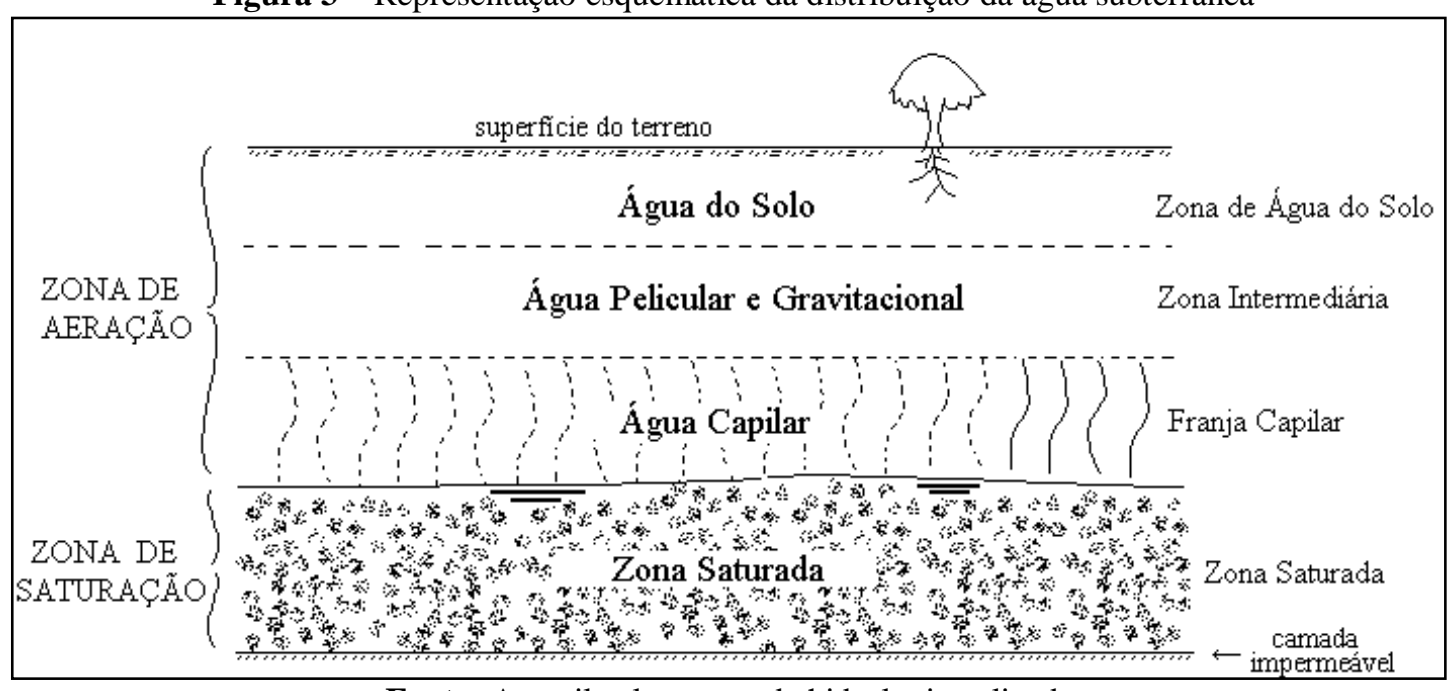

Fonte: Apostila elementos da hidrologia aplicada.

A água que adentra neste sistema, em específico da zona de aeração pode ser considerada de edáfica, que é dada em três formas, podendo ser a gravitativa, que é a água que escoa-se terreno adentro logo após a eventos pluviométricos. Já a água absorvida e/ou inserida às partículas do solo, pode ser denominada de pelicular, àquela que é retida nos interstícios (espaços microscópicos) das rochas é denominada de capilar.

Tangente ao armazenamento de água na área de saturação, dependem de variáveis por vez complexas, isso se referindo ao contexto geológico e litológico, já que estas variáveis determinam a percolação e infiltração da água na zona de saturação. No mapa 02 estão apresentados mapeamentos de unidades geológicas e as rochas que compõem a área de estudo: 
Mapeamento do nível freático: uma análise subsidiada por geotecnologia

Manoel Reinaldo Leite; Lucas Augusto Pereira da Silva; Caio Vinícios Leite Sampaio

Mapa 02 - Unidades Geológicas e Rochas

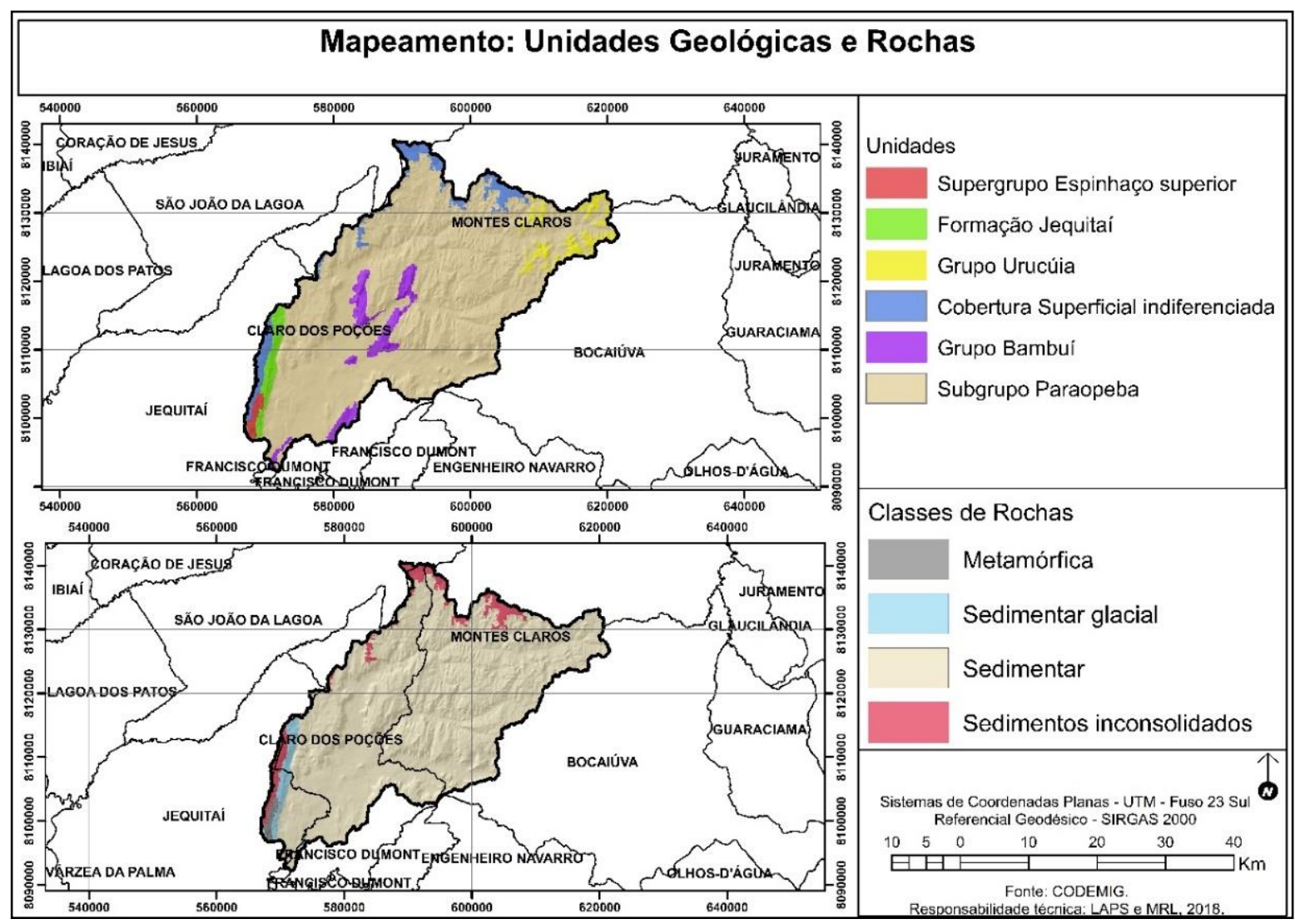

Fonte: CODEMIG

E para representar melhor sua distribuição espacial, nos gráficos 1 e 2 estão os percentuais destas variáveis na área de estudo:

Gráfico 1 - Distribuição em \% das Unidades Geológicas na Bacia do Rio São Lamberto

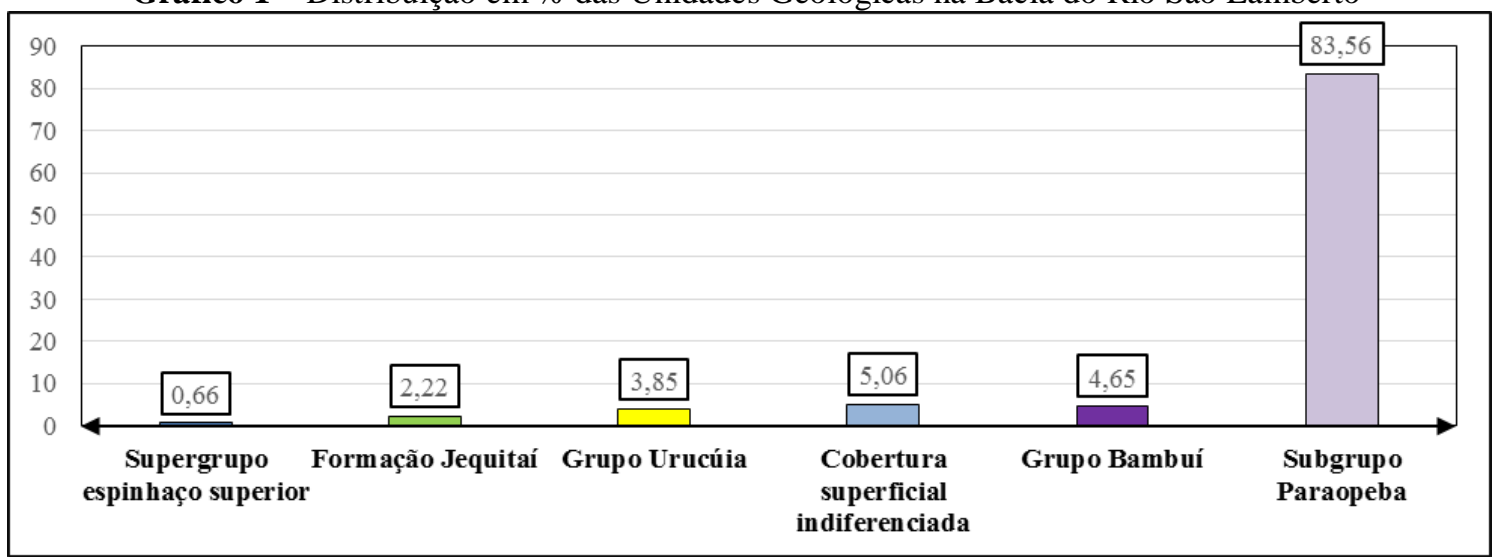

Fonte: CODEMIG. Responsabilidade técnica: LAPS e MRL, 2018. 
Mapeamento do nível freático: uma análise subsidiada por geotecnologia

Manoel Reinaldo Leite; Lucas Augusto Pereira da Silva; Caio Vinícios Leite Sampaio

Gráfico 2 - Distribuição em \% das Rochas na Bacia do Rio São Lamberto.

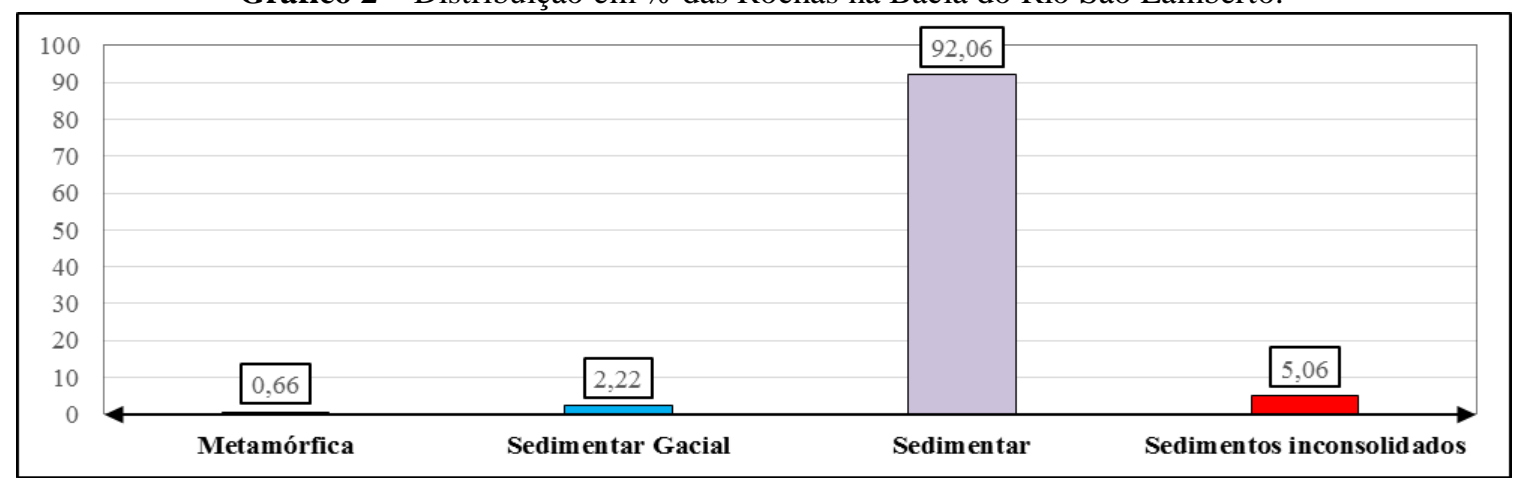

Fonte: CODEMIG. Responsabilidade técnica: LAPS e MRL, 2018.

É perceptível que quando às unidades geológicas o Subgrupo Paraopeba é o que possui maior percentual da área da bacia, sendo $9,88 \mathrm{~km}^{2}$, e em consonância com esta informação, vale observar também as rochas, já que o conjunto sedimentar possui maior percentual, sendo $92,06 \%$.

O entendimento disso é importante para ter noção da capacidade de armazenamento de água que a bacia possui isso porque segundo Leinz e Amaral (2001), as rochas são elementares nesta discussão, pois a porosidade das mesmas define significativamente a capacidade de armazenamento, e, ainda para estes autores, as rochas sedimentares são boas armazenadoras de água, visto seu nível de porosidade elevado.

Destarte, é necessário explanar que, o nível freático conforme visto em Boezio et al (2006) e Leinz e Amaral (2001) segue as cotas altimétricas de uma determinada área, ou seja, quanto maior for a altitude do relevo, maior serão os níveis freáticos para tal área. Os últimos autores supracitados mencionam o exemplo da Avenida Paulista no Estado de São Paulo e o Rio Tietê, onde os mesmos se encontram em cotas altimétricas diferentes, sendo a AV Paulista acima e o Rio abaixo, e o nível freático segue este comportamento da topografia. Na Mapa 03 estão representadas as cotas altimétricas da bacia do Rio São Lamberto e os pontos dos poços espacializados: 
Mapeamento do nível freático: uma análise subsidiada por geotecnologia

Manoel Reinaldo Leite; Lucas Augusto Pereira da Silva; Caio Vinícios Leite Sampaio

Mapa 03 - Hipsometria da Bacia do Rio São Lamberto.

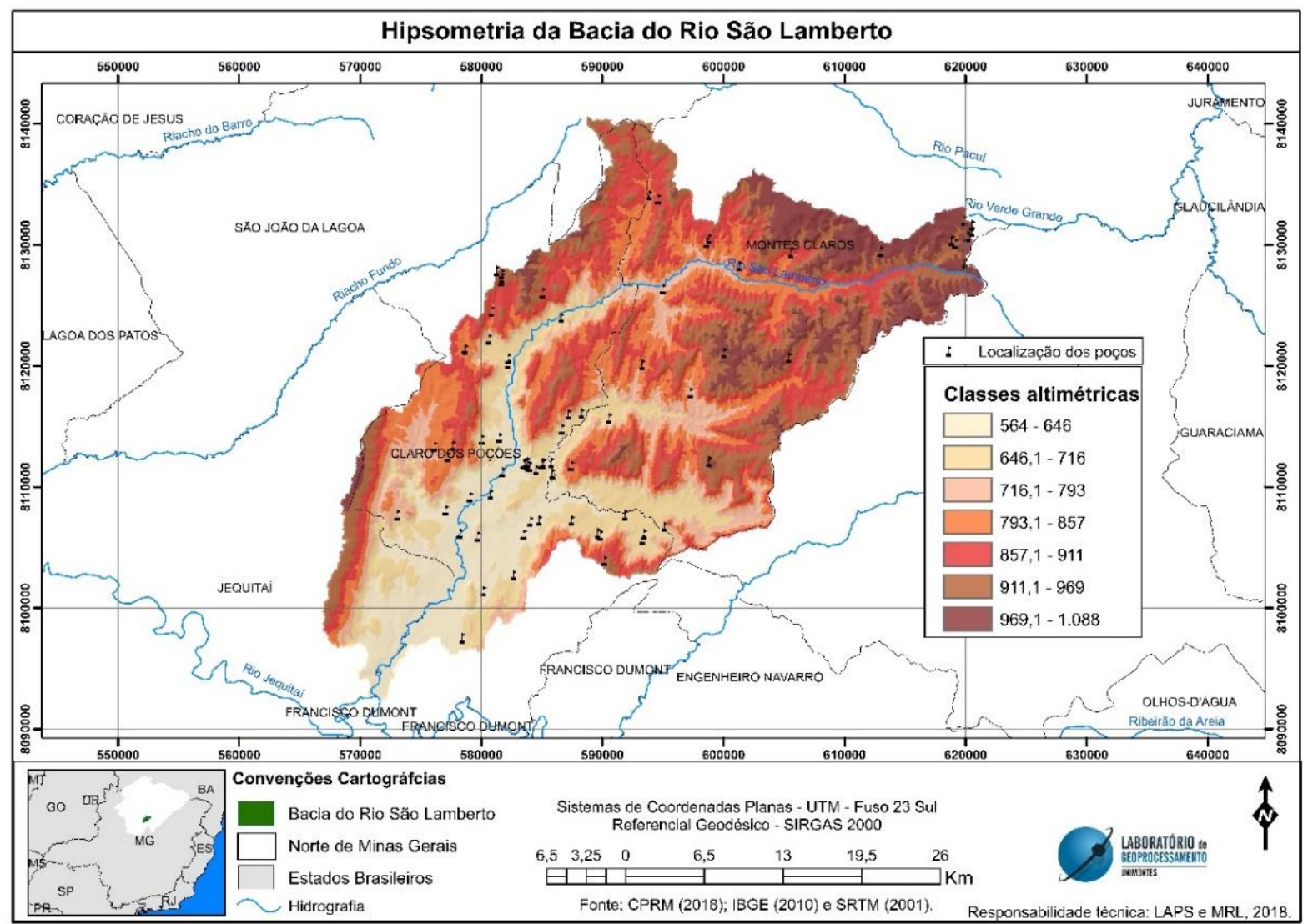

Observa-se que ao Sul da bacia, onde se dá o desaguamento do Rio São Lamberto a área é mais plana, estando entre as cotas altimétricas de 564 a 716 metros, as maiores altitudes, estão relacionadas a norte, nordeste e noroeste da bacia, a sudoeste também se encontra também tais cotas.

Quanto a seleção dos poços artesianos, observa-se que estes estão espacializados de maneira aleatória na bacia, variando de um relevo plano a um relevo montanhoso, de tal forma é necessário apresentar o nível estático dos poços, ou seja, o quanto foi perfurado em relevo para a obtenção de água, visto no gráfico 3: 
Gráfico 3 - Nível estático dos poços artesianos.

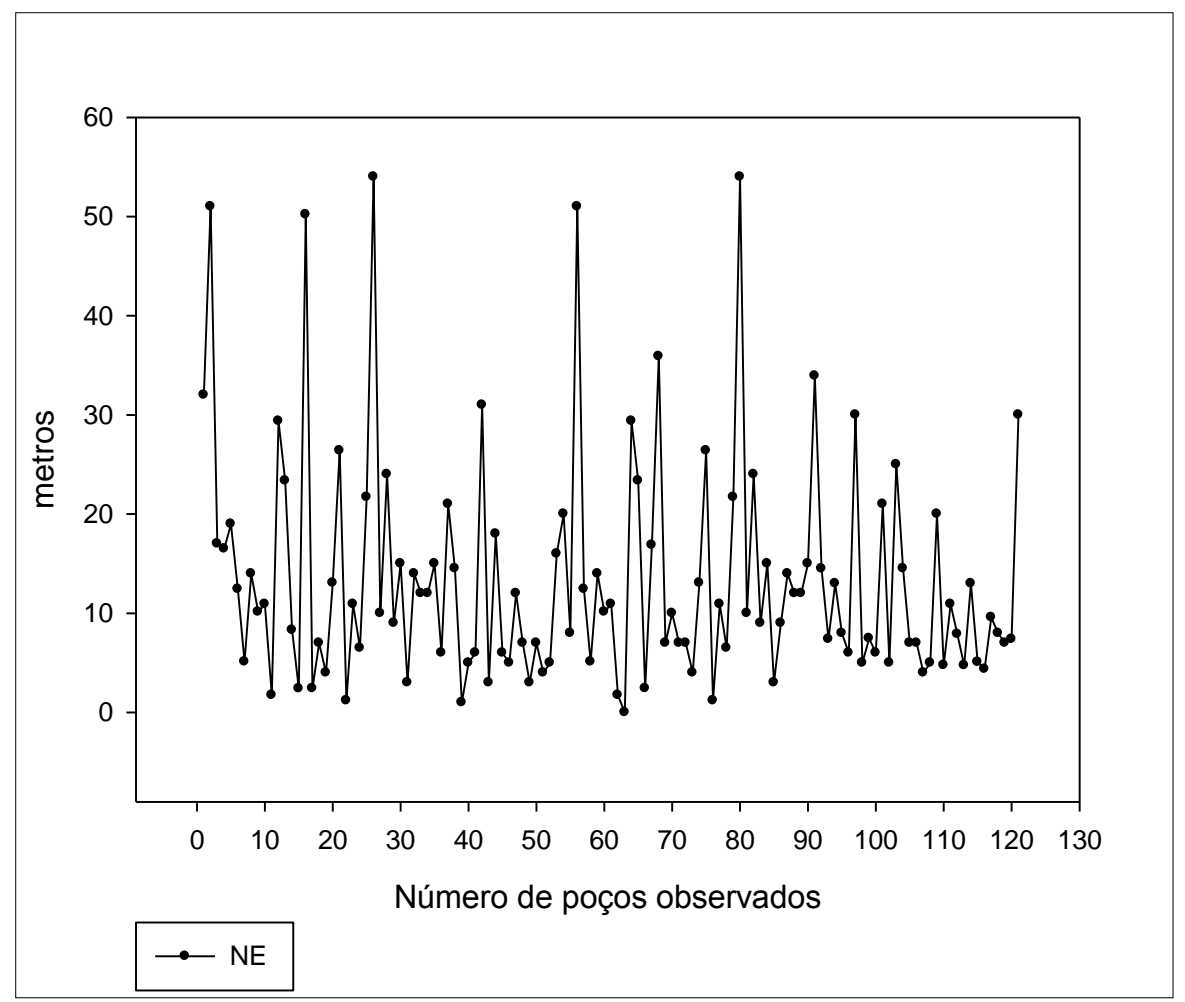

Fonte: CPRM, 2018. Responsabilidade técnica: LAPS e MRL, 2018.

Os níveis estáticos são bem diferenciados dentro da análise, variando de 0 a 54 metros de profundidade. $\mathrm{O}$ valor zero pode estar relacionado à aquíferos superficiais, onde a água está praticamente sobre a terra sem que precisar assim de furos para obtenção de água, este poço está localizado nas coordenadas métricas em 8106705 de latitude e 595148 de longitude tendo uma elevação de 718 metros no relevo e quanto a sua vazão, registrou $132,01 \mathrm{~m}^{3} / \mathrm{h}$, sendo esta vazão a maior de todos os poços analisados.

Dando sequência a análise e o proceder da metodologia, ao extrair a diferença entre o nível estático e a altitude do relevo no poço, obteve-se o nível freático dos poços, conforme são representados no gráfico 4. 


\section{Gráfico 4- Altitude do relevo e nível freático dos poços artesianos.}

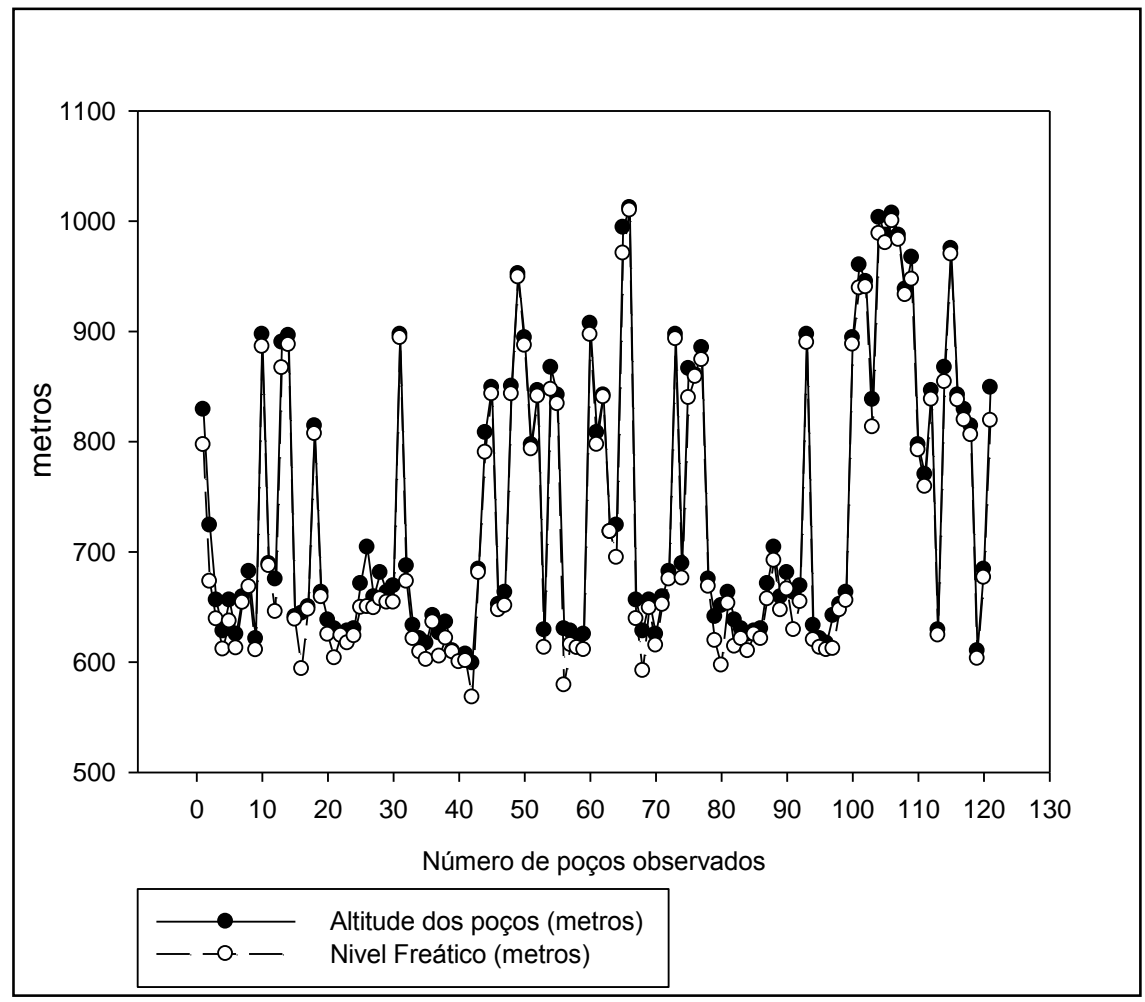

Fonte: CPRM, 2018. Responsabilidade técnica: LAPS e MRL, 2018.

Conforme já discutido, o gráfico 4 mostra que: o nível freático segue a cota altimétrica do relevo em tese. A fim de entender a relação estatística desses dados, é necessário fazer a relação de regressão linear para estas variáveis, no caso o $\mathrm{R}^{2}$, conforme descrito no gráfico 5 :

Gráfico 5 - Relação estatística.

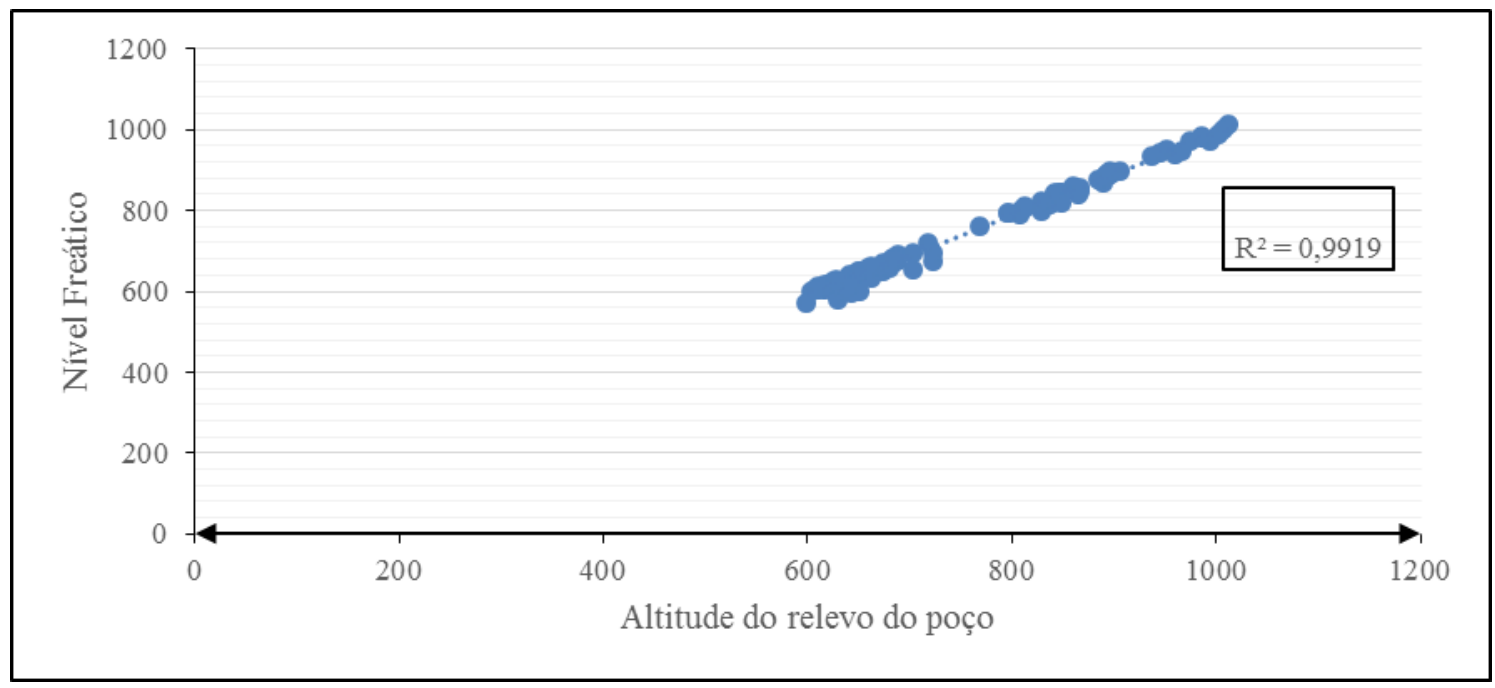

Fonte: CPRM, 2018. Responsabilidade técnica: LAPS e MRL, 2018. 


\section{Mapeamento do nível freático: uma análise subsidiada por geotecnologia}

Manoel Reinaldo Leite; Lucas Augusto Pereira da Silva; Caio Vinícios Leite Sampaio

O R $\mathrm{R}^{2}$ foi computado em $99 \%$ de correlação entre as variáveis, reforçando assim que o nível freático segue piamente as cotas altimétricas do relevo. Do ponto de vista analítico, é necessário fazer algumas interpretações acerca do poço onde o nível estático é zero, já que obviamente o nível freático é o mesmo em que se encontra a altitude do poço, ou seja 718 metros, podendo argumentar que o nível freático deste ponto se assimila à uma fonte superficial; e a formação destas fontes são advindas de contextos geológicos como prediz Leinz e Amaral (2001).

Para adentrar na análise da espacialização do nível freático, é de extrema importância mencionar que, ao analisar o mapa de nível freático e o de hipsometria, observa-se que o mapeamento de nível freático está 4 metros acima da cota topográfica de menor elevação da área, sendo que o intervalo da hispometria inicia-se em 564 e o nível freático em 568, 26 metros, e teoricamente isso alavancaria uma possível falha técnica do estudo, mas, salienta-se que: a menor altitude do relevo do poço representa uma cota altimétrica de 599 metros e um nível estático de 31 metros, e com a subtração estes valores são redefinidos para 568 metros de nível freático.

Destarte, essa diferença não representa uma falha técnica, mas sim que o estudo se baseou na análise por meio dos dados de campo, no caso, os poços artesianos. No mapa 04 está representado o nível freático da bacia do Rio São Lamberto.

Observa-se que o nível freático ao sul da Bacia é menos elevado, visto que essas áreas são de menores cotas altimétricas, e fazendo uma análise detalhada, pode-se dizer que nessas localidades o nível é raso, ou seja, está em maior proximidade com o relevo, no caso em específico o relevo plano.

Do ponto de vista econômico se bem organizado o tratamento técnico, estas áreas são as melhores para obter a água por este método, visto que isso fica evidente ao observar que a maioria dos poços está na região sul, centro-sul da bacia. 
Mapeamento do nível freático: uma análise subsidiada por geotecnologia

Manoel Reinaldo Leite; Lucas Augusto Pereira da Silva; Caio Vinícios Leite Sampaio

Mapa 04 - Nível Freático da Bacia do Rio São Lamberto.

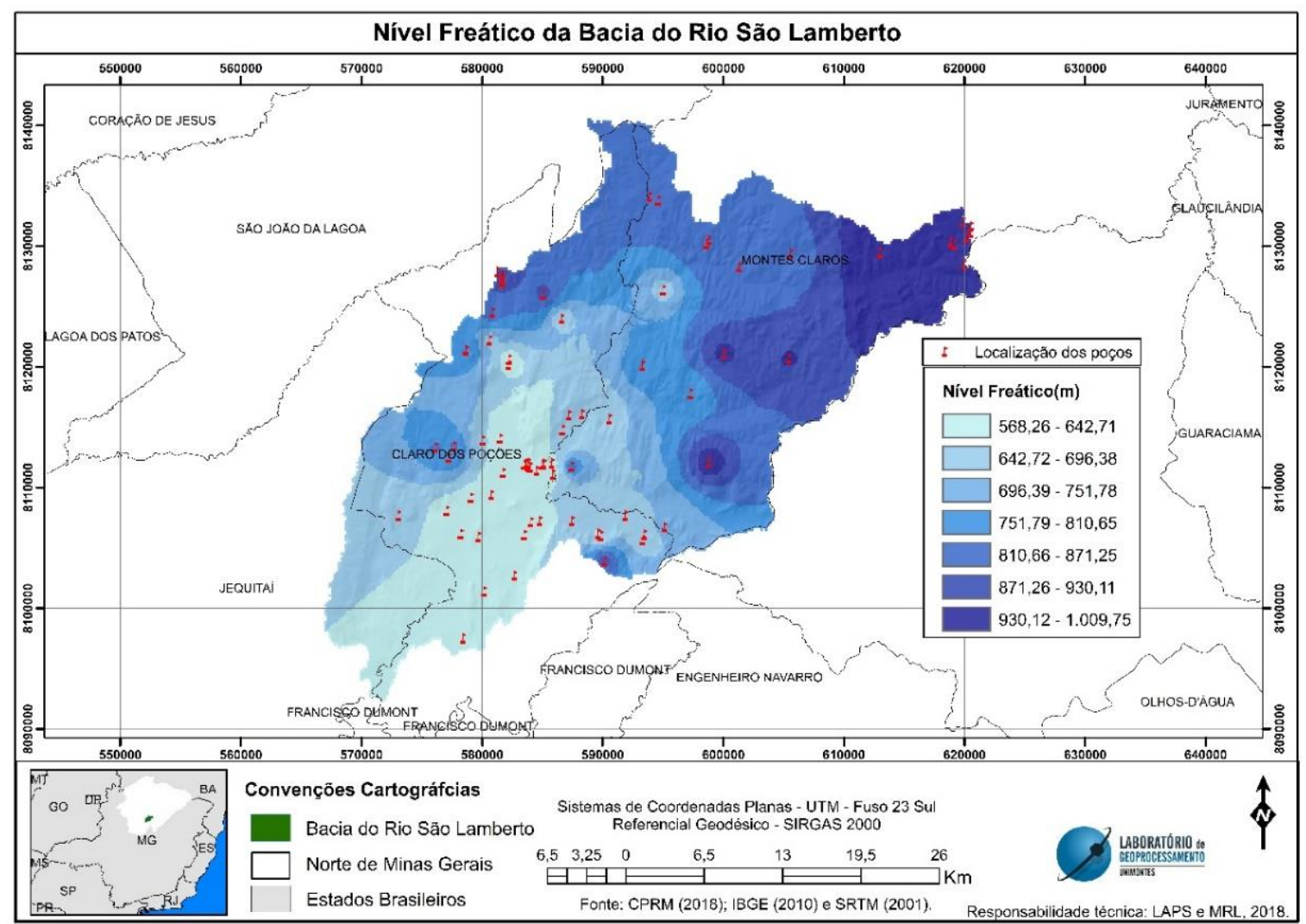

No entanto, é necessário ter uma visão geoambiental desta área, após análises observou-se que o uso e ocupação da terra apresenta um mosaico contraditório, como pode ser visto no mapa 05 :

Mapa 05 - Representação da parte Sul da Bacia.

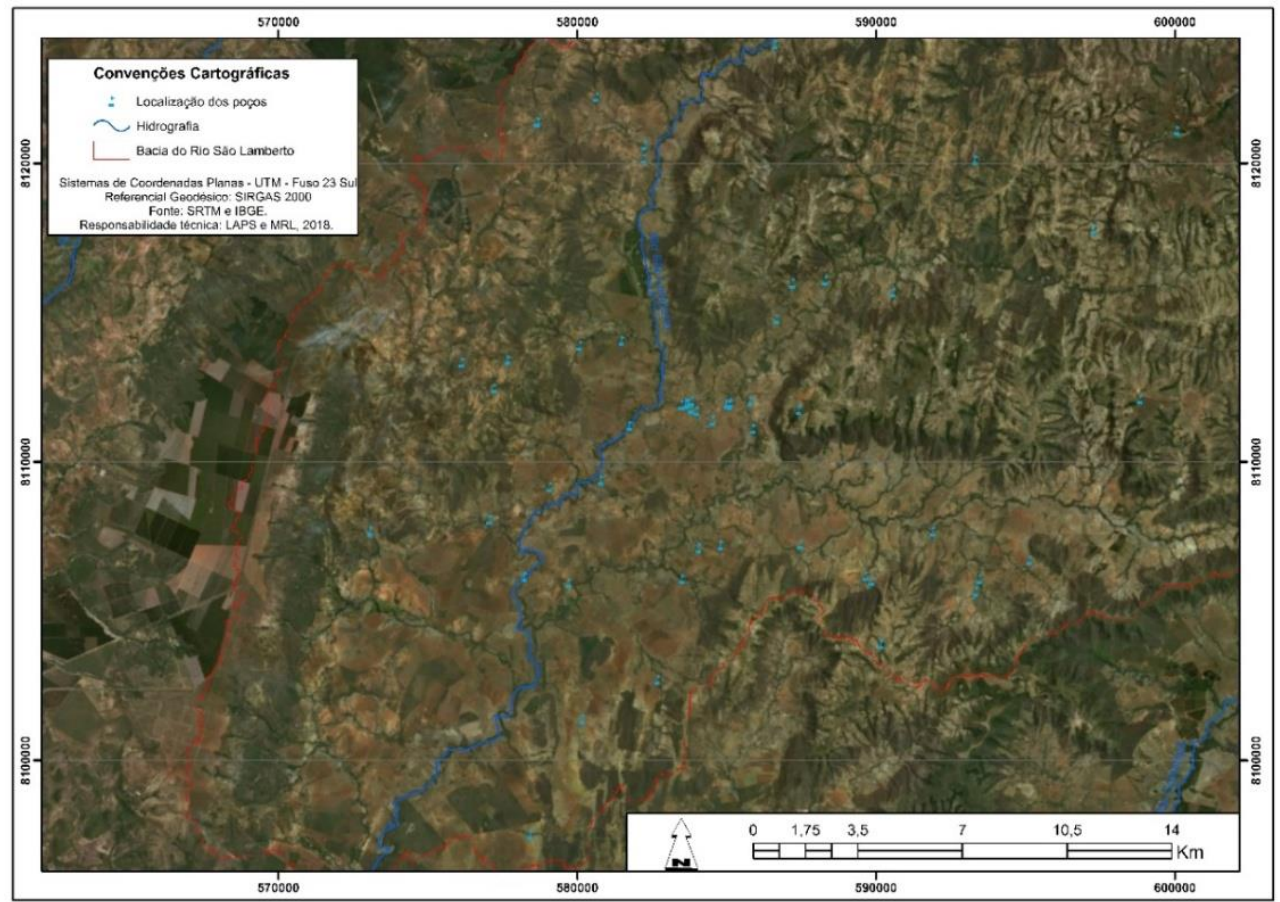




\section{Mapeamento do nível freático: uma análise subsidiada por geotecnologia}

Manoel Reinaldo Leite; Lucas Augusto Pereira da Silva; Caio Vinícios Leite Sampaio

No mapa 05, observa-se que a tonalidade marrom-amarelado dentro do limite da bacia possui uma fisionomia diferente das áreas de vegetação natural que por vez possui tonalidade verde, estas áreas são sistemas agropastoris, vegetação rala com antropização e solo exposto.

Dado este panorama, entende-se que o nível freático sendo relativamente raso nessas áreas tende a sofrer problemas ambientais, sobretudo com contaminação das áreas por agrotóxicos, e, ainda nesta perspectiva, como a presença de vegetação é escassa quando houver incidência de chuvas intensas a tendência é que a força dos índices pluviométricos cause erosão, e tende a acarretar em problemas com sedimentos a serem transportados para os corpos hídricos a jusante. E, vale salientar que esta falta de vegetação pode acarretar na diminuição do nível freático sendo que a infiltração no solo estará comprometida.

Ao observar os poços, chamou-se atenção também o número de poços nas áreas de relevo montanhoso, já que estas são os pontos de recarga hídrica e de extrema importância geomorfológica, hidrológica e ecológica para uma dada unidade hidrográfica e em consequência para as populações que residem nessa localidade. Isto pode acarretar em problemas de abastecimento caso não haja um dado cuidado técnico para usufruir deste bem tão procurado, a água.

Quanto ao uso da água, seja ele pequeno agricultor ou pelo grande empreendedor, deve contemplar as normas ambientais, seguindo rigorosamente os parâmetros impostos pelos órgãos ambientais. E nesse devir, pensar o território somente do viés econômico tende a acarretar problemas sérios aos recursos naturais, e diante disto é importante ter uma visão geográfica aguçada.

\section{CONSIDERAÇÕES FINAIS}

Este estudo se mostrou forte indicador para mapeamentos de nível freático, isso sendo de extrema importância para estudos ambientais, norteamentos de perfuração de poços, análises dinâmicas entre variáveis morfométricas e recursos hídricos.

O nível freático seguiu o comportamento das cotas altimétricas, sendo representada uma correlação estatística de $99 \%$ de aproximação, sendo um ótimo índice analítico.

Chama-se atenção para o nível da água na cota relevo plano, já que se apresentou como um nível raso, haja vista a pequena diferença entre o relevo e o nível estático, sendo isso algo que deve ser abordado e analisado em diversas oportunidades no campo científico e, sobretudo no bojo das políticas públicas. Quanto às áreas de relevo montanhoso, merece 
Mapeamento do nível freático: uma análise subsidiada por geotecnologia

Manoel Reinaldo Leite; Lucas Augusto Pereira da Silva; Caio Vinícios Leite Sampaio

atenção e destaque ímpar, já que são fundamentais para a manutenção dinâmica dos recursos hídricos, sendo áreas de recarga hídrica.

Foram encontrados poços perfurados com pouca profundidade, em especial mencionase o poço onde se obteve água a 0 metro de profundidade, e, foi com vazão elevada, podendo ser tratada como áreas de afloramento hídrico, onde merecem certo cuidado ambiental.

Do ponto de vista técnico, este trabalho se apresenta como uma proposta metodológica que pode vir a beneficiar diferentes escalas e áreas do conhecimento, e, podendo dar suporte técnico às políticas públicas para a gestão dos recursos hídricos. As Geotecnologias, b se apresentam com boas opções para estudos que necessitam de análises do espaço geográfico e, sobretudo considerando a dinâmica hídrica.

\section{REFERÊNCIAS}

ALLEN, R. G., TASUMI, M. AND TREZZA, R. SEBAL (Surface Energy Balance Algorithms for Land) Advanced Training and Users Manual - Idaho Implementation, version 1.0, 97 p., 2002.

ALMEIDA, M. I. S.; BORGES, M. G.; RODRIGUES, H. L. A. ANÁLISE COMPARATIVA DE FITOFISIONOMIAS EM ÁREAS DE BACIAS HIDROGRÁFICAS DO RIO SÃO LAMBERTO E DO RIO VACARIA, MINAS GERAIS MG COM USO DE SENSORIAMENTO REMOTO. REVISTA TOCANTINENSE DE GEOGRAFIA, v. 6, p. 139-139, 2017.

ALLEN, R.G.; PEREIRA, L.S.; RAES, D.; SMITH, M. Crop Evapotranspiration: guidelines for computing crop water requirements. Rome: FAO,1998. 279p. (FAO. Irrigation and Drainage paper, 56).

Banco de Dados Geomorfométricos do Brasil. Disponível em: <http://www.dsr.inpe.br/topodata/>. Acesso em: 10 Set. de 2017.

HAWKING, S.W. Breve História do Tempo. Do Big-Bang aos Buracos Negros. Rio de Janeiro: Rocco, 1988.

JACOB; Alberto Augusto Eichman; YOUNG, Andrea Ferraz. O uso de métodos de interpolação espacial de dados nas análises sociodemográficas. Disponível em: <http://www.abep.nepo.unicamp.br/encontro2006/docspdf/ABEP2006_388.pdf $>$. Acesso em: 10 Set. de 2017.

LEINZ, Viktor; AMARAL, Sérgio Estanislau. Geologia Geral. São Paulo: Companhia Editora Nacional, 2001.

BOEZIO Maria Noel Morales ; COSTA, João Felipe Coimbra Leite ; KOPPE, Jair Carlos . Cokrigagem colocada aplicada ao mapeamento do nível de água subterrânea. REM. Revista Escola de Minas (Impresso), v. 59, p. 159-164, 2006. 
Mapeamento do nível freático: uma análise subsidiada por geotecnologia

Manoel Reinaldo Leite; Lucas Augusto Pereira da Silva; Caio Vinícios Leite Sampaio

TUBELIS, A. E NASCIMENTO, F.J.L. do. Meteorologia Descritiva: fundamentos e aplicações brasileiras / Antônio Tubelis, Fernando José Lino do Nascimento. - São Paulo: Nobel, 1980. p. - 374.

VILlELA, S.M.; MATTOS, A. Hidrologia Aplicada. São Paulo: McGraw-Hill do Brasil, 1975. 244p.

VELOSO, G. A. Análise Espaço Temporal dos Componentes do Balanço de Radiação, Energia e Evapotranspiração, Usando Técnicas de Sensoriamento Remoto em Áreas Irrigadas do Projeto Jaíba/MG. Dissertação (Mestrado em Geografia) - Instituto de Geografia/IG, Universidade Federal de Uberlândia, Uberlândia, 2013.

ALVES SOBRINHO. T; VITORINO. A.C.T.; SOUZA. L.V.C.F.; GONÇALVES. M.C.; CARVALHO. D.F. Infiltração de água no solo em sistemas de plantio direto e convencional. Revista Brasileira de Engenharia Agrícola e Ambiental. Campina Grande, v. 7. n. 2. p. 191-196. 2003.

APHA; AWWA; WPCF. Standard methods for the examination of water and astewater. 21a ed.. Washington D.C.. USA. American Public Health Association. 2005.

BRASIL. A Evolução da Gestão dos Recursos Hídricos no Brasil / The Evolution of Water Resources Management in Brazil. Brasília: ANA. 2002. 68 p.

BRASIL. Ministério do Meio Ambiente, Conselho Nacional de Meio Ambiente, CONAMA. resolução CONAMA no 396, de 3 de abril de 2008.- In: Resoluções, 2008. Disponível em: <http://www2.mma.gov.br/port/conama/legiabre.cfm?codlegi=562>. Acesso em: 20. Jun. 2018.

LIBARDI, P.L. Dinâmica da Água no Solo. 2. ed. São Paulo. SP: Edusp. 2012. 352 p.

FREITAS, Vladimir Passos de. Águas, aspectos jurídicos e ambientais. $3^{\mathrm{a}}$ Edição Revista atualizada. Curitiba: Juruá, 2007.

BRASIL, Decreta o Código de Águas. Decreto no 24.643, de 10 de julho de 1934. Disponível em http://www.planalto.gov.br/ccivil_03/decreto/D24643.htm Acesso em: 26 nov. 2018.

ALMEIDA, Evolução histórica da proteção jurídica das águas no Brasil. Teresina: Jus Navigandi, ano 7, n. 60, nov. 2002. Disponível em https://jus.com.br/artigos/3421/evolucaohistorica-da-protecao-juridica-das-aguas-no-brasil Acesso em: 26 nov. 2018. 